\title{
Biofumigation potential of Indian mustard (Brassica juncea) to manage Rhizoctonia solani
}

\author{
Ibrahim Abdallah, Radwa Yehia* (1) and Mohamed Abdel-hady Kandil
}

\begin{abstract}
In Egypt, Rhizoctonia solani is an economically important fungal pathogen on many crops such as common bean causing serious yield losses. Biofumigation with Indian mustard (Brassica juncea), as a potential alternative to the restricted fumigant methyl bromide, is gaining attention in sustainable vegetable production. In this study, laboratory and greenhouse experiments were conducted to evaluate the biofumigation effect of B. juncea, used as dry plants, seed meal, seed powder, methanol extract, and fresh plants (at the vegetative and flowering stages), against $R$. solani. Results showed that hexane defatted seed meal was the most efficient one, followed by the seed powder, fresh plants at the flowering stage then fresh plants at the vegetative stage. The fungal inhibition rate was $61.5,50.2,49.9$, and $47.7 \%$, respectively. While the dry plants at both flowering and vegetative stage recorded the lowest suppressive effect (44.3 and $39.1 \%$, respectively). The findings open up the possibility of using the B. juncea in managing the root rot fungus, not only as a common green manure but also as a defatted seed meal.
\end{abstract}

Keywords: Biofumigation, Indian mustard, Rhizoctonia solani, Control

\section{Background}

Rhizoctonia solani is a soil-borne plant pathogenic fungus causing diseases on many economically important crops worldwide and is responsible for significant yield losses in a wide range of host plants, including agricultural and horticultural crops (Woodhall et al. 2007). $R$. solani caused a crop loss of $48 \%$ in stand establishment and $52 \%$ in seed yield of soybean (Handiseni et al. 2016). Chemical soil fumigant (i.e., methyl bromide) has been generally used to control the soil-borne pathogens. Despite methyl bromide efficiency in controlling a wide range of soil-borne plant diseases, this fumigant was phased out due to its ozone-depleting effect (Directive EC 128/2009) (Porter et al. 2010). Therefore, finding ozone friendly, safe, and sustainable alternative disease control option has become a necessity. Soil biofumigation was among the potential and suitable alternatives

\footnotetext{
* Correspondence: Radwayehia23@gmail.com

Department of Entomology and Pesticides, Faculty of Agriculture, Cairo University, Cairo, Egypt
}

\section{Springer Open}

for disease management. "Biofumigation" is a term used to describe the suppression of soil-borne pests and pathogens by brassica species such as canola (Brassica napus) and Indian mustard (Brassica juncea) in rotation or as green manure crops (Wang et al. 2014). The use of Brassica crops as a biofumigant has been successfully exploited for the management of soil-borne pathogens and is growing and gaining interest. The biofumigation technique is managed in several countries at a full-field scale, e.g., USA, Australia, Italy, the Netherlands, and some others (Tollsten and Bergström 1988). Brassica crops contain significant quantities of the thioglucoside compounds known as glucosinolates (GSLs). When plants are incorporated into the soil, the plant tissues are ruptured allowing the GSLs and myrosinase enzyme come into contact and are hydrolyzed to release various forms of volatile isothiocyanates (ITCs) (Vig et al. 2009). ITC compounds are known to have broad pesticidal activity including insecticidal, nematocidal, fungicidal, antibiotic, and phytotoxic effects (Yulianti et al. 2006). The

(c) The Author(s). 2020 Open Access This article is licensed under a Creative Commons Attribution 4.0 International License, which permits use, sharing, adaptation, distribution and reproduction in any medium or format, as long as you give appropriate credit to the original author(s) and the source, provide a link to the Creative Commons licence, and indicate if changes were made. The images or other third party material in this article are included in the article's Creative Commons licence, unless indicated otherwise in a credit line to the material. If material is not included in the article's Creative Commons licence and your intended use is not permitted by statutory regulation or exceeds the permitted use, you will need to obtain permission directly from the copyright holder. To view a copy of this licence, visit http://creativecommons.org/licenses/by/4.0/. 
isothiocyanates produced by mustard are called "Allylisothiocyanate" (AITC), which is very similar to the chemical fumigant metam sodium. Controlling $R$. solani through biofumigation has shown varying success. $B$. juncea cultivars ("Brand 199," "Ruby Streak," "Florida Broadleaf," and "Green Wave") consistently provided $>90 \%$ mycelial inhibition in vitro for managing rice sheath blight caused by $R$. solani (Handiseni et al. 2016). In addition, AITC released from mustard was shown to be suppressive to $R$. solani in a controlled laboratory study (Charron and Sams 1999). Moreover, significant $R$. solani reduction was observed in greenhouse assays and also in field tests, following soil incorporation of brassica plant tissues, including $B$. juncea (Larkin and Griffins 2007). B. juncea was proved to be rich in ITCs and well-known in bioassay screenings of Brassicaceae cultivars as the most effective biofumigant (Hanschen and Winkelmann 2020). Therefore, the objective of the present work was to evaluate the biofumigation effect of the Indian mustard as an antifungal agent for controlling $R$. solani under laboratory and greenhouse conditions.

\section{Materials and methods}

Fungicidal effect of Brassica juncea under laboratory and greenhouse conditions

Seeds of B. juncea (cultivar Balady) were obtained from the commercial market, Cairo, Egypt. Different treatments were tested in the laboratory and in the greenhouse as follows: plant extract, seed powder (SP), hexane defatted seed meal (DSM), fresh plants at vegetative stage (FVS), fresh plants at inflorescence emergence stage (FIS), dry plants at vegetative stage (DVS), and dry plants at inflorescence emergence stage (DIS).

\section{Plant materials and growth conditions}

The mustard plant was sown and grown in pots $(32 \mathrm{~cm}$ in diameter) under greenhouse conditions, $25 \pm 2{ }^{\circ} \mathrm{C}$, $75 \%$ relative humidity, and $16-\mathrm{h}$ photoperiod. Two growth stages were sampled; after 4 and 8 weeks of sowing. Plants were harvested and washed to remove any adhering soil before dividing the plant samples into whole plants, shoots, and roots. The samples of different plant parts were kept under room temperature $\left(25 \pm 2{ }^{\circ} \mathrm{C}\right)$ for drying, then homogenized to a fine powder, and stored at $-20{ }^{\circ} \mathrm{C}$ for further experiments.

\section{Inhibition of $R$. solani growth in the laboratory} Effect of Indian mustard methanol extract on the growth of R. solani

$R$. solani isolate was obtained from the Department of Vegetable Diseases at Plant Pathology Research Institute, Agriculture Research Center, Giza, Egypt. The extraction methodology of Doheny-Adams et al. (2017) was used with modification in which a total volume of $50 \mathrm{ml}$ absolute methanol was added to $7.6 \mathrm{~g}$ finely ground plant samples. Methanol was added, at the two main growth stages: vegetative stage (VS) and inflorescence emergence stage (IS). The samples were then kept in a water bath at $40{ }^{\circ} \mathrm{C}$ for $10 \mathrm{~min}$ with shaking at $120 \mathrm{rpm}$ and kept standing for $15 \mathrm{~min}$ before filtration through filter papers Whatman 1. The residue was re-extracted using the same procedure with combining the filtrates, and then methanol was evaporated using rotary evaporator under vacuum. The extract yield was weighed and sterilized, using a $0.45-\mu \mathrm{m}$ syringe filter and series of dilutions were prepared and tested by Petri dishes bioassay.

\section{Effect of Indian mustard fresh pieces on the growth of $R$. solani}

To examine the inhibitory effect of the released compounds from the crushed tissues, four treatments were tested with four replicates each, in addition to the untreated control. The roots and the shoots were tested at the two growth stages, above-mentioned, according to Stephens et al. (1999). One gram of separated root and $2.5 \mathrm{~g}$ of separated shoots were crushed in mortar and pestle for $0.5-1.5 \mathrm{~min}$ then placed in upside-down position inside the lids of agar plates that contained $5 \mathrm{~mm}$ of actively growing $R$. solani culture and placed on the middle of the plate. Drops of water were added to the crushed plant tissues then the plates were immediately sealed with parafilm and kept in the dark at $25 \pm 1{ }^{\circ} \mathrm{C}$. Control treatment were prepared in the same manner but without the addition of the plant materials to the dish. The mycelial growth inhibition was calculated according to the formula of Lahlali and Hijri (2010) as follows:

(Control-Treatment)/Control*100. The radial growth was recorded by measuring the mean colony diameter when the fungus in the control plates reached the margin of the plate. This technique ensured that only volatile hydrolysis products formed by macerated $B$. juncea tissues contacted the fungus mycelium.

\section{Inhibition of $R$. solani under greenhouse conditions Preparation of $R$. solani inoculate and soil infestation} The tested fungus was grown on a sand-oatmeal sterilized medium and incubated at $25{ }^{\circ} \mathrm{C}$ for 2 weeks in the incubator. A ratio of 1:1 sand/clay soil was autoclaved for $20 \mathrm{~min}$ at $121{ }^{\circ} \mathrm{C}$ and repeated for 3 days intervals (Berns et al. 2008). A weight of $1 \mathrm{~kg}$ of soil was then infested with the fungus at $8 \% \mathrm{w} / \mathrm{v}$. The artificially infested soil was then placed into cloth bags and moistened for one week to enhance the fungal growth. 
Inhibitory effect of different treatments of Indian mustard Infested soil was treated by the following treatments: SP, DSM, FVS, FIS, DVS, and DIS (Stephens et al. 1999; Salem and Mahdy 2015). These treatments were applied to the soil as weight/weight at $0.25,0.5,1$, and $2 \%$. The cloth bags, which contained infested soil with different treatments, were put inside plastic bags to prevent the loss of volatile hydrolysis products (due to damaged $B$. juncea tissues). The soil was moistened with the half field capacity prior to incubating for 7 days at $25 \pm 2{ }^{\circ} \mathrm{C}$. Two control treatments, healthy and infested with fungi, were prepared in the same manner but without adding mustard treatments. All treatments were replicated 4 times. After 2 weeks, germinated common bean seeds (Phaseolus vulgaris) were sown in pots $(10 \mathrm{~cm}$ in diameter $)$ with the rate of 2 seeds/pot and left for 20 days before recording the data. The following parameters were measured on the common bean seedlings:

(1) disease severity index: each plant was scored for damping-off severity and early root/hypocotyl damage using the 1-9 rating scale based on plant symptoms and root lesions (Peña et al. 2013), (2) plant fresh weight (g), and (3) the root and shoot length $(\mathrm{cm})$.

\section{Statistical analysis}

Data were statistically analyzed by one-way ANOVA with the software SPSS. Variance homogeneity and the comparison between means were analyzed by Duncan's multiple range test (Duncan 1955).

\section{Results and discussion Laboratory studies}

The extract of $7.6 \mathrm{~g}$ of dried plant materials with methanol yielded $2.17 \mathrm{~g}$ extract. The bioassay was then done as serial dilutions to determine the inhibitory effect of the plant under the study. The results revealed that the mustard extract reduced the mycelium growth of $R$. solani at the 2 growth stages, but IS (inflorescence emergence stage) extract was more effective than VS (vegetative stage) extract. As shown in Fig. 1, the effect was concentration-dependent as plant extract at 1/10 dilution $(\mathrm{v} / \mathrm{v})$ was the most effective, while $1 / 10000$ dilution had the lowest inhibitory effect. Also, data illustrated in Fig. 2 showed that shoots and roots at VS reduced the fungal mycelial growth by 12.2 and $30.4 \%$, respectively, Whereas shoots and roots at IS inhibited the growth by 57.1 and $82.2 \%$, respectively. In general, roots were more effective than shoots, and IS was more effective than VS (Fig. 3). The methanol extract was used first to determine whether the plant has antifungal activity and to test which plant growth stage had more biological activity. Doheny-Adams et al. (I2017) highlighted that glucosinolates are highly polar compounds, but sensitive to the heat and are significantly degraded in temperatures $\geq 75^{\circ} \mathrm{C}$ in $<10 \mathrm{~min}$. So in the present study, warm methanol was more preferable because it has a less hazardous effect and is more time- and cost-effective. So this technique preserves the volatile components, allowing the extract to exert its effect as a biofumigant against $R$. solani. The methanol extract revealed that the Indian mustard had inhibiting potential against $R$. solani at the two plant growth stages. It was clear that plants at the flowering stage had greater antifungal activity than the

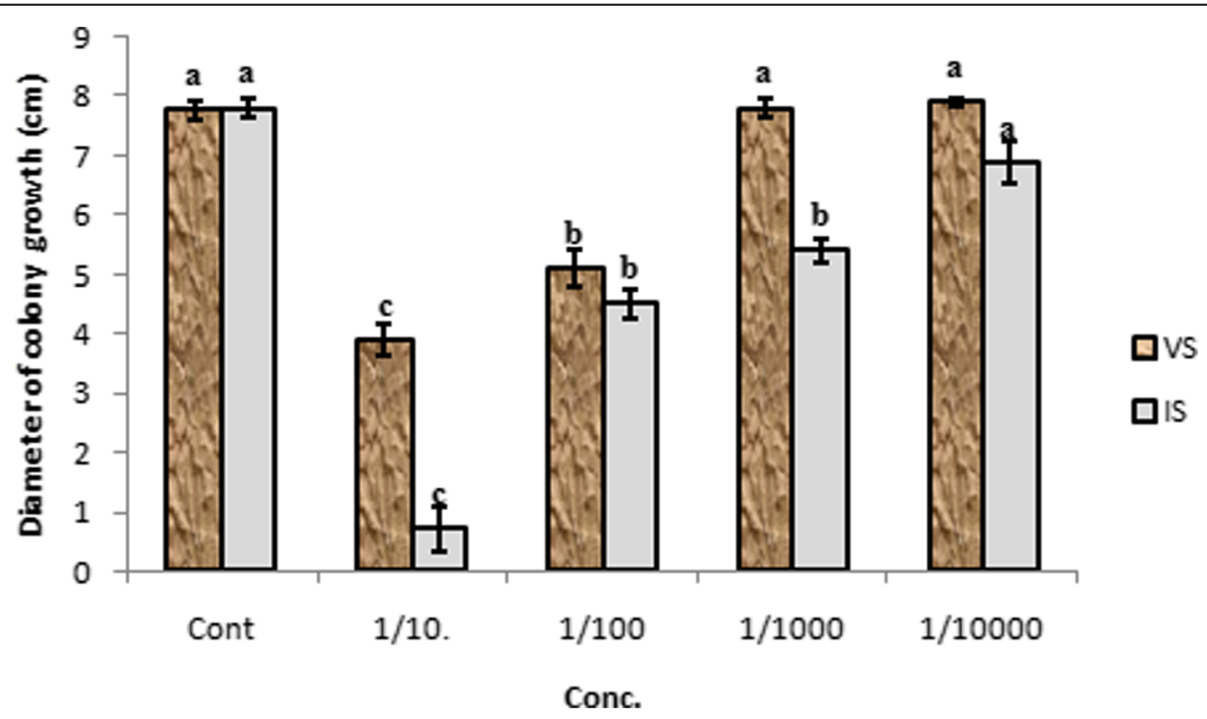

Fig. 1 Effect of mustard methanol extract on the growth of $R$. solani in the lab at two growth stages. *(VS) vegetative growth stage and (IS) inflorescence growth stage. Values have the same letter are not statistically different based on the Duncan's multiple range test at $p \leq 0.05$ 


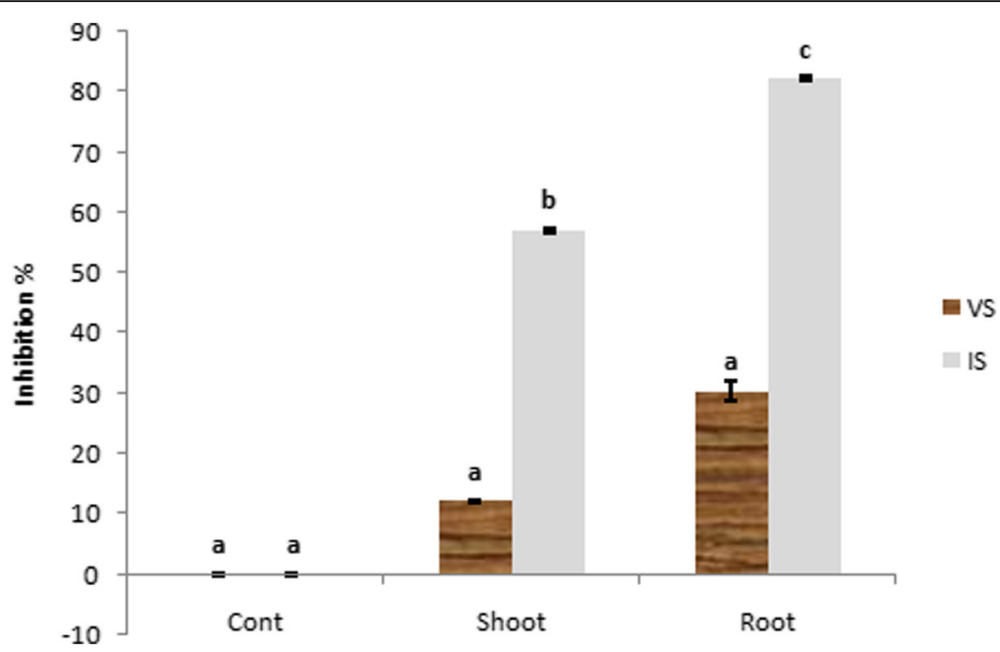

Fig. 2 Effect of mustard shoot and root pieces on the growth of R. solani in the lab at two growth stages. *(VS) vegetative growth stage and (IS) inflorescence growth stage. Values have the same letter are not statistically different based on the Duncan's multiple range test at $p \leq 0.05$

vegetative one. Several authors found similar results and recommended incorporation of some Brassica plants in the soil at the flowering stage (Stephens et al. 1999; Oliveira et al. 2011). Bellostas et al. (2004) attributed the differential efficacy during plant growth stages to the concentration changes of GSL (mainly sinigrin). Their study showed that when the plants reach the flowering stage, the GSL levels increased rapidly and concentrated in the reproductive organs. Additionally, the plant biomass reached its maximum during the flowering stage, which could provide more advantages for using mustard through that time. Obtained data examined the effect of different plant parts on the fungus at the lab level. There was a noticeable difference in activity between the root and the shoot parts, as root was more active than shoot. This finding is in agreement with Bellostas et al. 2004; Van Dam et al. 2009; Bhandari et al. 2015, and Villalta et al. 2016. Their studies revealed that, the root contains a high constant level of GSL during the plant life cycle, in contrast to the shoot which has a changeable concentration of GSL. This difference may be due to different factors such as genetics (Van Dam et al. 2009), environment, i.e., temperature (Sarwar and Kirkegaard 1998), and functional factors related to the defensive role of root against widespread soil pathogens. Second, the GSLs are classified as aliphatic, aromatic, or indole according to the side chain ( $\mathrm{R}$ group). The different GSL types result in different ITCs products

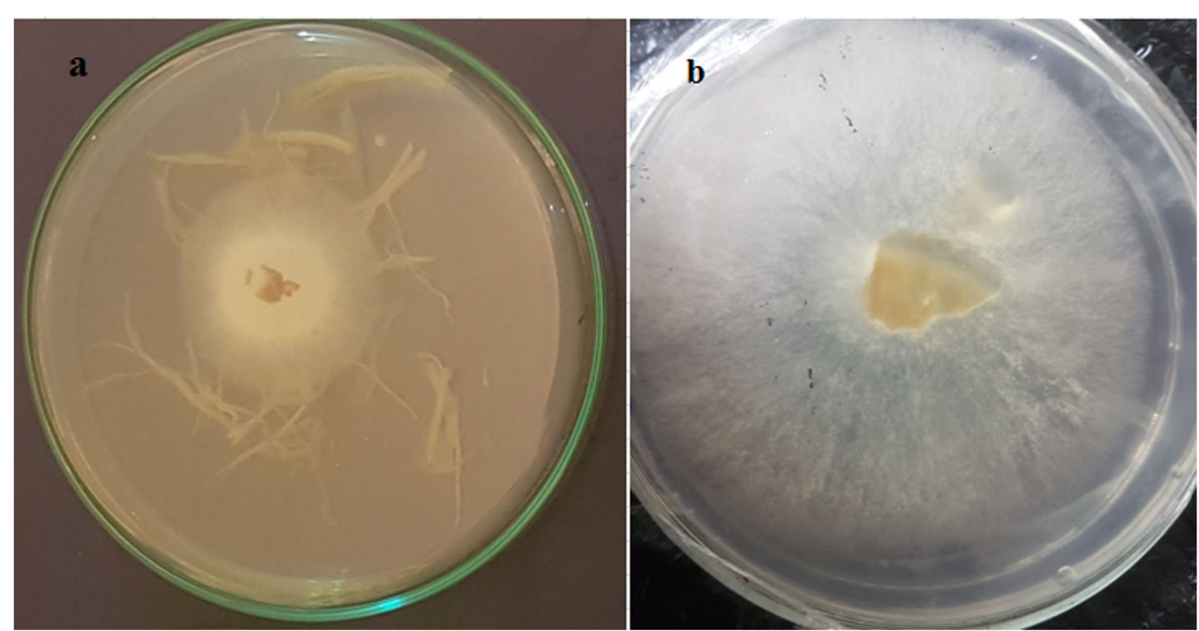

Fig. 3 Effect of mustard FIS root pieces on the growth of $R$. solani in the lab. a (FIS) fresh plants at inflorescence emergence, $\mathbf{b}$ control 
responsible for the toxic effect. The GSL type differs severely within the plant species; it also varies among the different parts within the same plant (Bhandari et al. 2015). Moreover, it was found that the shoot contains predominantly sinigrin as an aliphatic GSL, while the root contains a complex of GLS: sinigrin (aliphatic) and gluconasturtiin (aromatic). This variation of GSL types in root endows it the detrimental impact against various microorganisms. The root is also well functionally adopted against vigorous pathogenic invasions, which are widely spread in the soil (Bhandari et al. 2015).

\section{Greenhouse experiments}

Greenhouse results revealed that incorporation of soil with all mustard treatments (SP, DSM, FVE, FIS, DVS, and DIS) at different concentrations $(0.25,0.5,1$, and $2 \%$ reduced the fungal growth than the nonincorporated treatment. According to the disease severity index, obtained results showed that the defatted seed meal was the most effective treatment (Table 1). It inhibited the mycelial growth by $61.5 \%$. While SP, FIS, FVE, DIS, and DVS had an inhibitory effect of 50.2, 49.9, 47.7, 44.3, and 39.1\%, respectively. Also, it was observed that the inhibitory effect of different treatments was concentration-dependent, except for the dried plants, which showed opposite results as $2 \%$ DVS and DIS had the lowest effect (20.8 and $25.3 \%$, respectively). The most effective concentration for DVS and DIS was 0.25 and $1 \%$, which inhibited the fungus by 70.1 and $63.4 \%$, respectively. The disease severity degree was in direct correlation with the plant fresh weight. The fresh weight of common bean seedlings treated with $2 \%$ of DSM, FIS, SP, and FVS was $100,94.5,81.3$, and $52.3 \%$ compared to the healthy untreated control, respectively (Table 2). While this value at $0.25 \%$ of DSM, FIS, SP, and FVS was 55.7, 51.3, 51.5, and 21.5\%, respectively. Also, it was observed that the length of the root and the shoot was clear and direct indicators for the plant development, which reflected on the fresh weight of the common bean (Figs. 4 and 5). Using DSM considered the most effective treatment, followed by FIS and SP, while dry materials had the lowest effect. These findings agree with Oliveira et al. 2011 and Michel 2014. Likewise, Shaban et al. (2011) indicated that mustard seed meal was the most effective treatment as it reduced the root rot and wilt disease incidence by 87.5 and $87.8 \%$, respectively. Recent studies showed that using Brassicaceae seed meal alone or in combination with other techniques has promising results in controlling pre-plant diseases (Hanschen and Winkelmann 2020). On the other hand, Michel (2014) found that applying mustard hay in soil infested with Verticillium dahlia on tomato had no effect. Thus, the average root rot of tomato plants at the end of the trial had tremendously increased. He concluded that the effect of mustard hay was a long-term effect, and the number of $V$. dahlia microsclerotia was not influenced shortly after incorporation. Lazzeri et al. (2004) attributed the higher efficacy of the mustard seeds, and the DSM, specifically, to the high content of GSL than the other plant parts. Mustard seeds contain $35-40 \%$ oil (Anonymous 2019) which may bind to the GSL and subsequently prevent the enzymatic activity. But when the seeds are deoiled, the GSL become free from any bonds, and as a result, it has become available for the enzymatic reaction, and thus produces ITC. Another factor was discussed by Oliveira et al. (2011), which is the persistence time of ITC in the soil. Their study showed that the ITCs release rate and persistence time in the soil were very high in DSM, followed by SP. The present study on dried plant material showed that it had the least fungicidal effect which agrees with Lazzeri et al. 2004 who underlined the influence of the drying process on the GSL content. That probably led to the

Table 1 Effect of different mustard treatments with different concentrations (as percentage of the control) on the disease index of 20-days common bean seedlings infected with R.solani

\begin{tabular}{|c|c|c|c|c|c|c|c|c|c|c|c|c|}
\hline \multirow{3}{*}{$\begin{array}{l}\text { Treat. } \\
\%\end{array}$} & \multicolumn{12}{|c|}{ Treatment } \\
\hline & \multicolumn{2}{|l|}{$\overline{F V S}$} & \multicolumn{2}{|l|}{ FIS } & \multicolumn{2}{|l|}{ DVS } & \multicolumn{2}{|l|}{ DIS } & \multicolumn{2}{|l|}{$S P$} & \multicolumn{2}{|l|}{ DSM } \\
\hline & $\bar{M}$ & $\%$ & $\bar{M}$ & $\%$ & $\bar{M}$ & $\%$ & $\bar{M}$ & $\%$ & $\bar{M}$ & $\%$ & $\bar{M}$ & $\%$ \\
\hline I.Cont & $6.7 \pm 0.3$ & 100 & $6.3 \pm 0.3$ & 100 & $6.7 \pm 0.3$ & 100 & $6.3 \pm 0.3$ & 100 & $6.7 \pm 0.3$ & 100 & $6.7 \pm 0.3$ & 100 \\
\hline 0.25 & $5 \pm 0$ & 25.3 & $4.3 \pm 0.3$ & 31.7 & $2 \pm 0$ & 70.1 & $4 \pm 0$ & 36.5 & $4.3 \pm 0.3$ & 35.38 & $4 \pm 0$ & 40.2 \\
\hline 0.5 & $3.3 \pm 0.3$ & 50.7 & $3.3 \pm 0.3$ & 47.6 & $4 \pm 0$ & 40.2 & $3 \pm 0$ & 52.3 & $3.7 \pm 0.3$ & 44.7 & $3 \pm 0$ & 55.2 \\
\hline 1 & $3 \pm 0$ & 55.2 & $3 \pm 0$ & 52.3 & $5 \pm 0$ & 25.3 & $2.3 \pm 0.3$ & 63.4 & $3 \pm 0$ & 55.2 & $2 \pm 0$ & 70.1 \\
\hline 2 & $2.7 \pm 0.3$ & 59.7 & $2 \pm 0$ & 68.2 & $5.3 \pm 0.3$ & 20.8 & $4.7 \pm 0.3$ & 25.3 & $2.3 \pm 0.3$ & 65.6 & $1.3 \pm 0.3$ & 80.6 \\
\hline AVG & $47.7 \%$ & & $49.9 \%$ & & $39.1 \%$ & & $44.3 \%$ & & $50.2 \%$ & & $61.5 \%$ & \\
\hline
\end{tabular}

The values are expressed as mean \pm standard error

$M$ mean, I.Cont Infested control, FVS fresh plants at vegetative stage, FIS fresh plants at inflorescence emergence, DVS dry plants at vegetative stage, DIS dry plants atinflorescence stage, SP seed powder, DSM hexane defatted seed meal 
Table 2 Effect of different mustard treatments with different concentrations (as a mean and a percent of the control) on the fresh weight of 20-days common bean infected with R.solani

\begin{tabular}{|c|c|c|c|c|c|c|c|c|c|c|c|c|}
\hline \multirow{3}{*}{$\begin{array}{l}\text { Conc. } \\
\%\end{array}$} & \multicolumn{12}{|c|}{ Treatment } \\
\hline & \multicolumn{2}{|l|}{ FVS } & \multicolumn{2}{|l|}{ FIS } & \multicolumn{2}{|l|}{ DVS } & \multicolumn{2}{|l|}{ DIS } & \multicolumn{2}{|l|}{$S P$} & \multicolumn{2}{|l|}{ DSM } \\
\hline & $M$ & $\%$ & $M$ & $\%$ & $M$ & $\%$ & $M$ & $\%$ & $M$ & $\%$ & $M$ & $\%$ \\
\hline Cont. & $6.5 \pm .0$ & 100 & $3.7 \pm .0$ & 100 & $6.1 \pm .3$ & 100 & $3.4 \pm .1$ & 100 & $6.4 \pm .0$ & 100 & $6.1 \pm .0$ & 100 \\
\hline 0.25 & $1.4 \pm .0$ & 21.5 & $1.9 \pm .3$ & 51.3 & $3.6 \pm .1$ & 59 & $2.6 \pm .0$ & 76.4 & $3.3 \pm .2$ & 51.5 & $3.4 \pm .3$ & 55.7 \\
\hline 0.5 & $2.4 \pm .1$ & 36.9 & $2.4 \pm .2$ & 64.8 & $3.8 \pm .1$ & 62.2 & $2.9 \pm .1$ & 85.2 & $3.3 \pm .7$ & 51.5 & $4.6 \pm .2$ & 75.4 \\
\hline 1 & $3.3 \pm .2$ & 50.7 & $2.9 \pm .1$ & 78.3 & $3.8 \pm .1$ & 62.2 & $3.1 \pm .1$ & 91.1 & $4.2 \pm 1.3$ & 65.6 & $5.4 \pm .1$ & 88.5 \\
\hline 2 & $3.4 \pm .2$ & 52.3 & $3.5 \pm .2$ & 94.5 & $3.1 \pm .2$ & 50.8 & $2.3 \pm .0$ & 67.6 & $5.2 \pm .03$ & 81.3 & $6.1 \pm .1$ & 100 \\
\hline
\end{tabular}

The values are expressed as mean \pm standard error

$M$ mean, FVS fresh plants at vegetative stage, FIS fresh plants at inflorescence emergence, DVS dry plsnts at vegetative stage, DIS dry plants atinflorescence stage, $S P$ seed powder, DSM hexane defatted seed meal

glucosinolates leakage and myrosinase activity loss, which results in decreasing the efficacy.

In general, Brassicas particularly mustard revealed a potential benefit in controlling root rot disease, where the use of methyl bromide has been banned. In this regard, Lord et al. (2011) pointed out that the biocidal activity of the glucosinolates released from $B$. juncea is comparable with the efficacy of chemical pesticides and antibiotics. Accordingly, synthetic pesticides, such as methyl bromide, could be replaced by Brassica plants (Rokunuzzaman et al. 2016).

\section{Conclusion}

Biofumigation with Indian mustard can be exploited in soil fumigation in different methods particularly, as fresh plants in the common green manure, and seed meal after oil extraction based on the laboratory and greenhouse conditions. Further studies are needed to assess

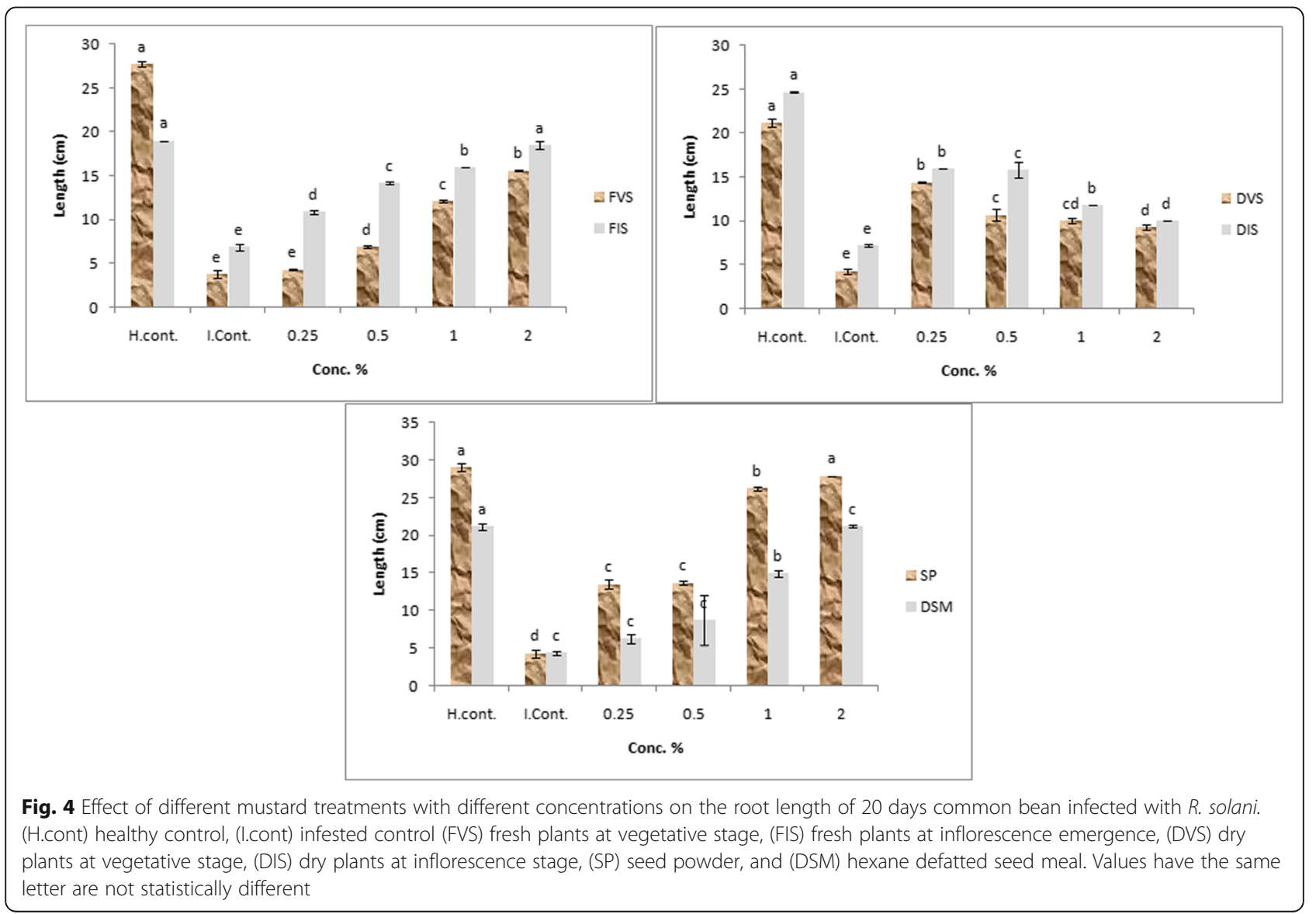




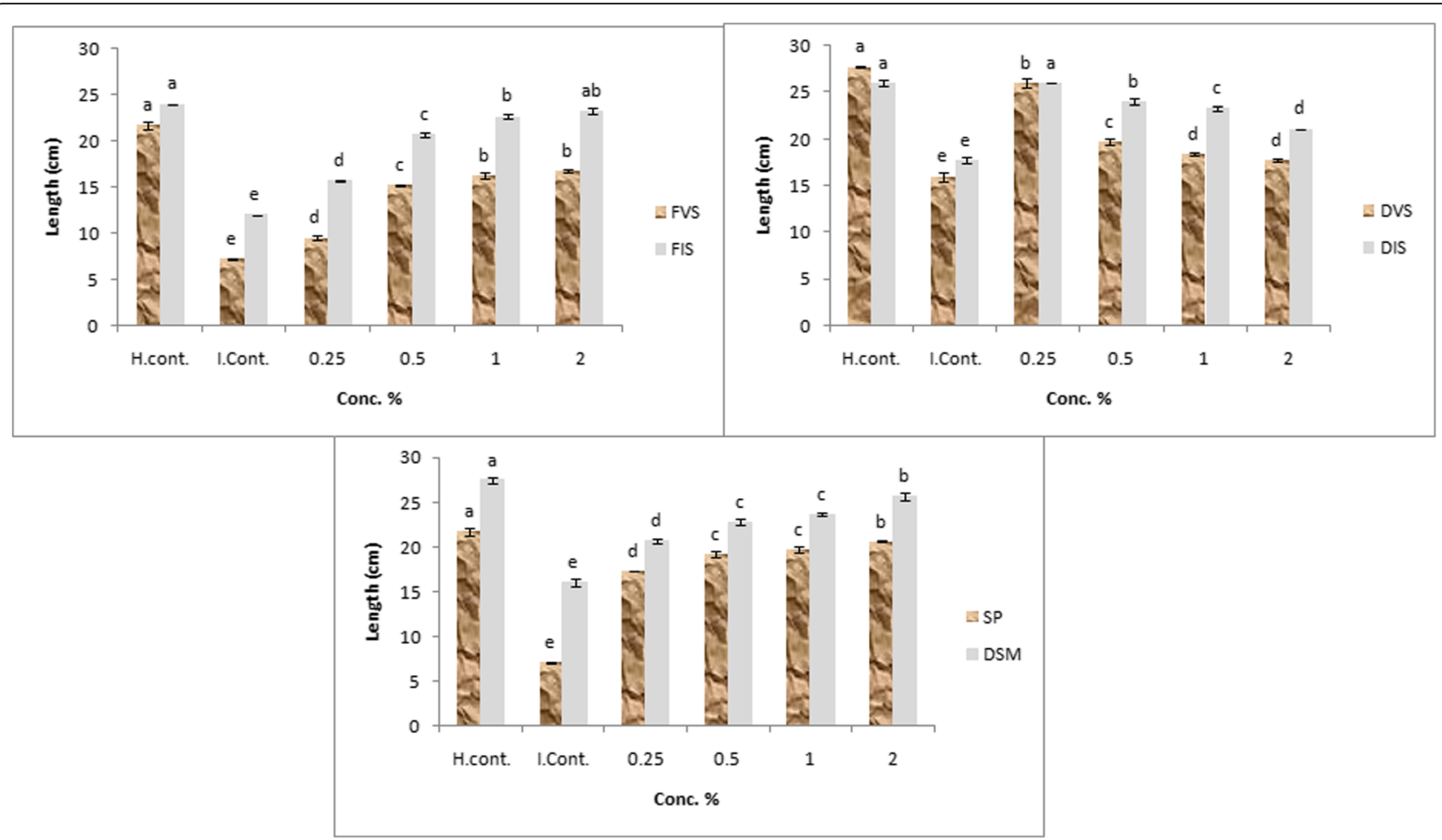

Fig. 5 Effect of different mustard treatments with different concentrations on the shoot length of 20 days common bean infected with $R$. solani. (H.cont) healthy control, (I.cont) infested control (FVS) fresh plants at vegetative stage, (FIS) fresh plants at inflorescence emergence, (DVS) dry plants at vegetative stage, (DIS) dry plants at inflorescence stage, (SP) seed powder, and (DSM) hexane defatted seed meal. Values have the same letter are not statistically different

the biological activity of this promising plant under natural field conditions. These first results open new perspectives for the application of biofumigation in plant protection and management. Biofumigation has advantages over other disease control methods, since it is used to reclaim soils contaminated with heavy metals and adds organic matter to the soil. Hence, what gives an advance for biofumigation is its ability to work as biopesticide and simultaneously as a soil-improvement tool. Farmers should be aware of the usefulness of this technique, in order to be implemented in their farming systems.

\section{Abbreviations}

DIS: Dry plants at inflorescence emergence stage; DSM: Hexane defatted seed meal; DVS: Dry plants at vegetative stage; FIS: Fresh plants at inflorescence emergence stage; FVS: Fresh plants at vegetative stage; IS: Inflorescence emergence stage; SP: Seed powder; VS: Vegetative stage

\section{Acknowledgements}

Not applicable for this study.

\section{Authors' contributions}

All authors designed the experiments. IA and MAK supervised and coordinated the laboratory work, results analysis, and manuscript drafting. RY performed the experiments and wrote the manuscript. All authors read and approved the final manuscript.

\section{Funding}

Not applicable for this study
Availability of data and materials

The data and material used during the current study are available from the corresponding author on reasonable request.

\section{Ethics approval and consent to participate}

Ethical approval and consent to participate are not required for this study.

\section{Consent for publication}

Not applicable for that section.

\section{Competing interests}

The authors declare that they have no competing interests.

Received: 5 May 2020 Accepted: 6 July 2020

Published online: 27 July 2020

\section{References}

Anonymous (2019) Government of Saskatchewan. Mustard Production Manual. Cited in https://saskmustard.com

Bellostas N, Sørensen JC, Sørensen H (2004) Qualitative and quantitative evaluation of glucosinolates in cruciferous plants during their life cycles. Agroindustria 3:1-10

Berns AE, Philipp H, Narres HD, Burauel P, Vereecken H, Tappe W (2008) Effect of gamma-sterilization and autoclaving on soil organic matter structure as studied by solid state NMR, UV and fluorescence spectroscopy. Eur J Soil Sci 59:540-550

Bhandari SR, Jo JS, Lee JG (2015) Comparison of Glucosinolate Profiles in Different Tissues of Nine Brassica Crops. Molecules 20:15828-15841

Charron CS, Sams CE (1999) Inhibition of Pythium ultimum and Rhizoctonia solani by shredded leaves of Brassica species. J Amer Soc Hort Sci 124:462-467

Doheny-Adams T, Redeker K, Kittipol V, Bancroft I, Hartley SE (2017) Development of an efficient glucosinolate extraction method. Plant Methods 13:1-14

Duncan B (1955) Multiple ranges and multiple F test. Biometrics 11(1-42):11 
Handiseni M, Jo YK, Lee KM, Zhou XG (2016) Screening Brassicaceous Plants as Biofumigants for Management of Rhizoctonia solani AG1-IA. Plant Dis 100: 758-763

Hanschen FS, Winkelmann T (2020) Biofumigation for Fighting Replant Disease-A Review. Agronomy, 10:1-16

Lahlali R, Hijri M (2010, FEMS) Screening, identication and evaluation of potential biocontrol fungal endophytes against Rhizoctonia solani AG3 on potato plants. 311:152-159

Larkin RP, Griffins TS (2007) Control of soil-borne potato diseases using Brassica green manures. Crop Prot 26:1067-1077

Lazzeri L, Leoni O, Manici LM (2004) Biocidal plant dried pellets for biofumigation. Ind Crop Prod 20:59-65

Lord J, Lazzeri L, Atkinson H, Urwin P (2011) Biofumigation for control of pale potato cyst nematodes: activity of Brassica leaf extracts and green manures on Globodera pallid in vitro and in soil. J Agric Food Chem 59:7882-7890

Michel W (2014) Ten years of biofumigation research in Switzerland. Asp Appl Biol 126:1-10

Oliveira RDL, Dhingra OD, Lima AO, Jham GN, Berhow MA, Holloway RK, Vaughn SF (2011) Glucosinolate content and nematocidal activity of Brazilian wild mustard tissues against Meloidogyne incognita in tomato. Plant Soil 341:155-164

Peña PA, Steadman JR, Eskridge KM, Urrea CA (2013) Identification of sources of resistance to damping-off and early root/hypocotyl damage from Rhizoctonia solani in common bean (Phaseolus vulgaris L.). Crop Prot 54:92-99

Porter I, Pizano M, Besri M, Scott M, Paul F (2010) Progress in the global phase out of methyl bromide and the relative effectiveness of soil disinfestations strategies. Acta Hortic 883:59-66

Rokunuzzaman M, Hayakawa A, Yamane S, Tanaka S, Ohnishi K (2016) Effect of soil disinfection with chemical and biological methods on bacterial communities. Egypt J Basic Appl Sci 3:141-148

Salem MS, Mahdy ME (2015) Suppression of root-knot nematode through innovative mustard biofumigation. FOFJ 3:41-50

Sarwar M, Kirkegaard JA (1998) Biofumigation potential of brassicas. II. Effect of environment and ontogeny on glucosinolate production and implications for screening. Plant Soil 201:91-101

Shaban WI, El-Barougy E, Zian AH (2011) Control of lupine Fusarium wilt by biofumigation with mustard and canola seed meal. Tunis J Plant Prot 6:87-98

Stephens PM, Davoren CW. Wicks T(1999) Effect of methyl bromide, metham sodium and the biofumigants Indian mustard and canola on the incidence of soil-borne fungal pathogens and growth of grapevine nursery stock Australas Plant Path 28: 187-196

Tollsten L, Bergström G (1988) Headspace volatiles of whole plants and macerated plant parts of Brassica and Sinapis. Phytochemistry 27:4013-4018

Van Dam NM, Tytgat TOG, Kirkegaard JA (2009) Root and shoot glucosinolates: a comparison of their diversity, function and interactions in natural and managed ecosystems. Phytochem Rev 8:171-186

Vig AP, Rampal G, Thind TS, Arora S (2009) Bio-protective effects of glucosinolates -A review. LWT-Food Sci Technol 42:1561-1572

Villalta O, Wite D, Riches DA, Guiano J, Chandolu V, Scoble C, Donald C, Porter JJ, Mattner SW (2016) The concentration of 2-propenyl glucosinolate in biofumigant crops influences their anti-fungal activity (in-vitro) against soilborne pathogens. J AgricChem Environ 5:38-45

Wang Q, Ma Y, Yang H, Chang Z (2014) Effect of biofumigation and chemical fumigation on soil microbial community structure and control of pepper Phytophthora blight. World J Microbiol Biotechnol 30:507-518

Woodhall JW, Lees AK, Edwards SG, Jenkinson P (2007) Characterization of Rhizoctonia solani from potato in Great Britain. Plant Pathol 56:286-295

Yulianti T, Sivasithamparam K, Turner DW (2006) Response of different forms of propagules of Rhizoctonia solani AG2-1 (ZG5) exposed to the volatiles produced in soil amended with green manures. Ann Appl Biol 148:105-111

\section{Publisher's Note}

Springer Nature remains neutral with regard to jurisdictional claims in published maps and institutional affiliations.

\section{Submit your manuscript to a SpringerOpen ${ }^{\circ}$ journal and benefit from:}

- Convenient online submission

- Rigorous peer review

- Open access: articles freely available online

- High visibility within the field

- Retaining the copyright to your article

Submit your next manuscript at $\boldsymbol{\nabla}$ springeropen.com 